\title{
Building effective partnerships: the role of trust in the Virus Resistant Cassava for Africa project
}

\author{
Obidimma C Ezezika ${ }^{1,2,3^{*}}$, Justin Mabeya ${ }^{1}$, Abdallah S Daar ${ }^{1,4,5}$
}

\begin{abstract}
Background: Virus Resistant Cassava for Africa (VIRCA) is an agricultural biotechnology public-private partnership (PPP) comprising the Donald Danforth Plant Sciences Center (DDPSC), National Agricultural Research Organization (NARO) of Uganda and Kenya Agricultural Research Institute (KARI). The project seeks to develop virus-resistant cassava for farmers in Kenya and Uganda. Yet, there is much public skepticism about the use of genetically modified (GM) crops and private sector involvement in Africa. This case study sought to understand the role of trust in the VIRCA partnership.
\end{abstract}

Methods: We conducted semi-structured, face-to-face interviews to obtain stakeholders' views on the challenges to, and practices for, building trust in the VIRCA partnership. Interviewee responses, together with relevant documents and articles, were analyzed to generate descriptions of how trust is operationalized in this evolving agbiotech PPP. Data were analyzed based on recurring and emergent themes from the interviewee responses.

Results: Various factors undermine and build trust in agbiotech PPPs. Individual and institutional enthusiasm and detailed collaborative agreements stipulating partner roles and responsibilities are likely to enhance trust among partners. On the other hand, negative perceptions propagated by international partners about the capacities of African institutions and scientists, coupled with slow regulatory processes in Africa, are likely to be impediments to trust building.

Conclusions: Based on the findings of this study, we have derived four key lessons. First, differences in the capacity of the partner institutions and individuals should be respected. Second, technical and infrastructural capacity support for regulatory processes in Africa must be built. Third, detailed agreements and open and transparent partner practices during project implementation are necessary to dispel perceptions of inequality among partners. Fourth, institutional and individual commitment to succeed is important in initiation of the project. These lessons can be used by other agbiotech PPPs as a guide for building trust among partners and with the community.

\section{Background}

The importance of cassava in sub-Saharan Africa

Agbeli, the name for cassava in one of the indigenous languages spoken in Ghana, Togo and Benin, translates to "there is life"; this translation reflects the importance many Africans attribute to the crop [1]. Cassava is to Africa what rice is to Asia and potatoes to Ireland. A third of Africa's population, estimated at over 250 million people, depend directly on cassava as their primary

\footnotetext{
* Correspondence: obidimma.ezezika@srcglobal.org

'Sandra Rotman Centre, University Health Network and University of

Toronto, Toronto, Ontario, Canada

Full list of author information is available at the end of the article
}

source of calories, with their per capita consumption in the range of 200 to 400 kilograms [2].

Uganda and Kenya are two of the five East African Community (EAC) countries. Uganda leads the other four Kenya, Tanzania, Rwanda and Burundi- in cassava production. Cassava is a food security ${ }^{\mathrm{a}}$ crop and the second most important source of carbohydrate in Uganda after plantains [3]. For Ugandans, cassava is important for the achievement of the Millennium Development Goals (MDGs) on food security [4]. Its tuberous root is a source of food and can be used industrially as a source of starch. Its leaves are used as a vegetable and the stem as firewood. Ugandans have therefore coined the expression 'wamalako nga Muwogo' in one of their ethnic languages, which can

\section{() Biomed Central}


be translated to "you are as complete as cassava" because of its usefulness.

\section{Current barriers to the potential role of cassava in African agriculture}

Despite the obvious significance of cassava in sub-Saharan Africa, and specifically in East Africa, cassava is described as an 'orphan crop' [5]. An orphan crop is defined as "that crop species which has been under-exploited for its contribution towards food security, health (nutritional/medicinal), income generation and environmental effects" [6]. Unlike major commercial crops like maize and soybean, there has been little effort to improve orphan crops via genetic engineering because they are rarely traded in international markets. Paradoxically, studies indicate that investment in genetically modified (GM) orphan crops like cassava will immensely benefit its producers [5] and therefore contribute significantly to the economic wellbeing of millions of people in sub-Saharan Africa.

Cassava is also tolerant to the adverse climatic conditions and poor soils prevalent in sub-Saharan Africa [2]. This attribute, combined with its high carbohydrate content, makes it a popular crop for families in sub-Saharan Africa. Unfortunately, cassava is threatened by two diseases: cassava mosaic disease (CMD) and cassava brown streak disease (CBSD) [2]. CMD is caused by cassava mosaic viruses (CMV) [7]. In the early 1990s, CMD became a significant burden to the agriculture sector in Uganda and western Kenya. The spread of the disease in Uganda led to a $64 \%$ reduction in the yield of cassavafrom a high of 3.6 million tonnes in 1989 to 2.08 million tonnes in 1994-threatening food security in the country [3]. The disease spreads between Uganda and western Kenya, where cassava is a staple food crop [8], through the sharing of planting materials by farmers across the KenyaUganda border [9].

By the year 2000, the use of cassava varieties with CMD resistance had led to a recovery in the production of cassava, which surpassed the pre-1990 levels [3]. However, CBSD began to re-emerge in 2004 in high altitude areas, therefore rendering the aforementioned varieties vulnerable [10]. CBSD is caused by two different species of cassava brown streak virus (CBSV) [11] and its means of transmission and distribution resembles that of CMD. With CBSD, even the most CMD-tolerant cassava varieties such as "2961" cannot avoid getting infected. The impact of CBSD is much more severe than that of CMD. On Tuesday $25^{\text {th }}$ May 2010, "Deadly cassava disease hits Uganda" [12] was the headline of an article in Uganda's leading national daily, the New Vision. The news flash about CBSD appearing six years after its re-emergence in 2004 [10] emphasized the magnitude of the threat posed by the virus disease on cassava yield.
In addition to an overall reduction in yield caused by CBSD, the edible tuberous roots of cassava show severe necrosis and are unfit for human consumption. On the $31^{\text {st }}$ of May 2010, the New York Times published a story about a Ugandan farmer who displayed cassava roots affected by CBSD and stated that even "pigs refuse it" [13]. This means that the crop, once infected by CBSD, is greatly abhorred by its consumers. The re-emergence of CBSD in eastern Africa also posed a double threat to CMD-sensitive crops, since the two pathogens can simultaneously infect the same cassava plant [10]. Both diseases can leave complete crops devoid of edible vegetation, adversely affecting household food security. The Virus Resistant Cassava for Africa (VIRCA) project, an agricultural biotechnology public-private partnership (PPP), was formed to develop virus-resistant varieties of cassava to deliver to farmers in the region for management of CMD and CBSD.

\section{The history and partnership of VIRCA}

The expression "opportunities multiply as they are seized" best depicts the initial stages of implementing the VIRCA project. The project began in 2006 when the then Director of International Programs at the Donald Danforth Plant Sciences Centre (DDPSC) toured Kenya, Uganda, Tanzania, South Africa and Malawi in order to find partners to conduct field trials for virus-resistant cassava, a transgenic technology that had been developed by DDPSC. At this early stage, DDPSC chose to partner with the Kenya Agricultural Research Institute (KARI) in Kenya and the National Agricultural Research Organization (NARO) in Uganda because of the former's experience in conducting trials on transgenic sweet potato and the latter's enthusiasm and experience in cassava research. In 2006, at a meeting in Uganda between the DDPSC and NARO, the Director of International Programs at DDPSC observed enthusiasm and willingness from the executives of NARO's cassava programme to partake in the project. As a result, the VIRCA project was organized by three core partnersDDPSC, NARO and KARI-in addition to other collaborators, including: the Monsanto Company, Monsanto Fund, United States Agency for International Development (USAID), and BioCassava Plus (see Additional file 1 for short profiles of the partners and collaborators). The primary goal of the project is to develop farmerpreferred cassava varieties resistant to CMD and CBSD, the two viral diseases responsible for the greatest yield loss of cassava. The secondary goal of the project is to increase research ownership and capacity in the target countries: Uganda and Kenya [14]. The project is organized into phase I (2006-2010) and phase II (20112015). The project aims to provide virus-resistant 
cassava varieties to farmers by 2015 for improved production and food security [15].

\section{The roles of the VIRCA partners and collaborators} DDPSC took the lead in research and capacity building while NARO and KARI led in the identification of farmerpreferred varieties and technology testing in the field. During phase I, funding was provided by the Monsanto Fund and USAID. [16], while the Monsanto Company provided their proprietary enabling technologies royaltyfree and DDPSC developed some of the technologies which confer cassava with disease resistance [5]. USAID awarded the DDPSC a US \$2.5 million grant for phase I. Further funding to support phase II of the project has been provided by the Bill and Melinda Gates Foundation and the Monsanto Fund (the primary responsibilities of the partners and collaborators are outlined in Additional file 2).

During phase I, the project focused on research along four steps: the identification of the target cassava varieties, the generation of transgenic events, confined field trials (CFTs) to test efficacy and biosafety, and regulatory approval for commercialization [17]. During this phase, the activities of VIRCA were harmonized with those of BioCassava Plus ${ }^{\mathrm{b}}$, which is also managed by the DDPSC [18]. The aim of the BioCassava Plus project is to develop improved cassava varieties with enhanced bio-available levels of zinc, iron, protein, vitamin A, and vitamin E, as well as reduced quantities of toxic cyanogenic glycosides and improved post-harvest durability (see Additional file 3 for an outline of the project phases and activities). With regards to capacity building, Uganda has developed advanced biosafety facilities and several CFTs for a number of crops in addition to cassava as a result of this project [14].

\section{The importance of trust in agbiotech PPPs}

Trust among the partners and with the community has been identified as an important element of effective PPPs [19]. Factors affecting the establishment, development, and maintenance of inter-personal and inter-organizational trust can either ensure or compromise the success of agbiotech projects. Agbiotech PPPs often face skepticism and resistance due to the public's lack of trust in genetically engineered crops and the involvement of the private sector. While the public sector views the intentions of the private sector with suspicion $[20,21]$ due to fear that multinational biotech companies seek to take advantage of poor nations [22], the private sector views the public sector as slow and inefficient and resistant to change [21].

In this study we therefore focused on understanding the role of trust in the VIRCA partnership-specifically, trust among the partners on the one hand and with the community on the other. The objectives of the study were to: 1) describe trust-building practices in the development of the VIRCA project; 2) describe the challenges associated with trust-building in the partnership and; 3 ) determine what makes these practices effective or ineffective. The findings of this study provide lessons on the role of trust in agbiotech PPPs and can be applied to similar projects in Africa to mitigate the consequences of mistrust commonly associated with agbiotech PPPs.

\section{Methods}

Data were collected by conducting interviews with key informants who are knowledgeable about the project; reviewing publicly available project documents and research articles; and through direct observations.

We received Research Ethics Board (REB) approval from the University Health Network, University of Toronto for conducting the case study. Interviewees were identified first by making a list of key individuals associated with the project based on the stakeholders groups as identified in the research protocol. This list was then populated further through snowball sampling through the Sandra Rotman Centre's Social Audit Project [23] using stakeholder informants who were familiar with the VIRCA Project. A total of 22 interviewees were identified through this process, 12 of whom were invited for interview (those who were closely linked to activities of phase I of the project) and eight interviewed. The other four were unavailable for various reasons. Potential interviewees were sent an invitation, which included an explanation of the case study series, to participate in the interview. Those who consented to participate were informed that the interview would be recorded, transcribed verbatim and then analyzed. Those interviewed were drawn from each of the three partner institutions: NARO, DDPSC and KARI. The interviewees included executives from the Cassava Programme in Uganda, the National Crop Resources Research Institute (NACRRI), the KARI Biotechnology Centre, the International Programs at the DDPSC, and the Bill and Melinda Gates Foundation, as well as the project officers from Kenya and Uganda.

The interviews took place in Uganda, Kenya, Zanzibar and the United States - at the convenience of the interviewees. The interviews were face-to-face and each lasted approximately one and a half hours. A semi-structured interview guide was used and included questions on the interviewees' background, their understanding of the project, and their interpretation of the word trust. The interviews further explored the interviewees' perception of trust among the partners and with the public, apparent challenges to trust building and observed trust-building practices. Finally, interviewees were asked for advice on how to improve trust in agbiotech PPPs (see Additional file 4 for sample questions from the interview guide). Data was analyzed based on recurring and emergent themes to 
create a comprehensive narrative on how trust is understood and built among the partners and with the community.

\section{Results and discussion}

We found that the stakeholders' understanding of trust and its elements informs the perspective with which they identify the challenges and practices of trust building and the expected outcomes. According to our interviewees, factors that contribute to the success of PPPs include capability (technical competence and ability to follow the law); enthusiasm to succeed; access to finances; strong leadership; qualified personnel; and appropriate agreements with other partners. The interviewees further pointed out that, aside from these factors, there were no special practices intended to build trust.

\section{VIRCA partners' understanding of trust}

The interviewees understood trust to be an important aspect of a relationship [between parties] that allows them to develop confidence in each other. For example, an interviewee from NARO explained that trust is what binds partners together. Further, interviewees said building trust requires time, in order for partners to understand each other's roles and expectations. One interviewee described a form of 'competence trust': trust is based on the kind of outcomes of the activities in which the partners are engaged. According to an interviewee from NARO, competence was evident during initial efforts in organizing the project when NARO's historical successes (outcomes) in breeding cassava for virus resistance were recognized by DDPSC. Other elements of trust identified by the interviewees include mutual respect for partner roles, sincerity and transparency.

\section{Trust-building challenges}

Negative perceptions about African scientists and institutions

NARO expressed concerns about attitudes at DDPSC regarding the integrity and capacity of African scientists and institutions to undertake the VIRCA project. According to NARO, the perceptions pertained to the corruption that bedevils many African governments. According to an interviewee from NARO, DDPSC scientists believed that they had "not seen Africa using facilities given to them; they [the facilities] bec[a]me white elephants." From the perspective of the scientists at NARO, these perceptions elicited monitoring by DDPSC scientists, which conveyed a sense of paternalism and inequality against NARO and KARI, thereby threatening trust building among the partners.

However, some documented facts give DDPSC's perception some credence. A feature appearing in The New African in $2009^{\mathrm{c}}$ quoted a Swedish International
Development Agency (SIDA) official in Uganda saying, "a government in power will always use the money [development aid] as they wish. There is nothing stopping them to use it as they wish." This statement was made in reference to the Ugandan government's diverting of SIDA aid to the war against the Lord's Resistance Army (LRA) in northern Uganda instead of supporting the running of rural medical clinics, which later had to be closed.

DDPSC argued that their perception stemmed from underlying cultural differences between the partners, which made them cautious and curious about partners' actions. Unlike the DDPSC, however, the public in Kenya and Uganda have expressed their trust in the stewardship of KARI and NARO respectively, as was claimed by an interviewee from KARI. Over time, DDPSC became convinced by the work ethics of the African team members and was able to have more confidence in them.

\section{Low emphasis on communication and community} engagement

Interviewees reported a skewed emphasis in favor of the product development component at the expense of other components (such as regulatory, communication and outreach) and said the teams are not moving in tandem. This unequal emphasis on the project component was likely to introduce discontent among team members. They listed the positive results that would ensue if all the teams were brought on board together at the same time and moved consistently together in terms of information sharing and capacity building. This would contribute to enhanced team spirit, trust (between the teams), and productivity in the next phase of the project.

An interviewee from KARI stated that trust between the project and the community is "poor" and that farmers do not know much about the VIRCA project. According to Hawkins [24], there is a lack of accurate information among farmers in Africa due to the traditional research model, in which research works for, rather than with, farmers; this implies a situation in which farmers are not partners in the process of identifying problems and their solutions, which may, as a result, render such solutions innapropriate. An interviewee from DDPSC linked farmers' apparent lack of trust in the performance of biotechnology to their lack of background knowledge that would enable them to form their own opinions. There is therefore a need for creating awareness on the nature and performance of GM crops.

\section{Slow regulatory processes in the implementing countries}

Although Kenya's legal framework and experience in genetic modification work allowed it to engage with DDPSC before Uganda, Uganda gradually overtook Kenya in terms of implementing the project. The slow pace of the implementation of the project in Kenya was due to delayed regulatory processes, which contributed 
to deteriorating trust between KARI and DDPSC, as the latter interpreted the slowness as reluctance on the former's side. On the other hand, KARI stated that DDPSC did not readily provide the information necessary for regulatory approvals and therefore argued that DDPSC was to blame for the delay. According to one interviewee, this led DDPSC to threaten withdrawing their support for KARI, who, as a result, felt that DDPSC had less trust in them than they had in NARO.

NARO also underwent instances of delayed regulatory processes, as observed by DDPSC. NARO, however, argued that the delays were due to biological challenges and reorganization within the regulatory institutions. Midway through the first phase of the project, the Institutional Biosafety Committee (IBC) and National Biosafety Committee (NBC) in Uganda, the key regulatory institutions on biosafety, underwent changes in management. This meant that the new team needed to learn how the committees operate, which therefore led to the delays. At the same time, the VIRCA project initially solely targeted CMD. It was later on that CBSD, to which varieties already resistant to CMD were highly susceptible, re-emerged. This necessitated the project to adopt a new objective focusing on the development of CBSDresistant varieties that was originally not considered.

Investors of agbiotech in Africa consider regulatory processes to be slow and at costs not commensurate to the market size [25] because of limited capacity on the part of government and scientists, which tends to paralyze decision making. Though the speed of regulatory approvals in both Uganda and Kenya improved as the regulators became more confident in the applicants, the delays demanded the deadline for product delivery to be extended - from 2013 to 2015.

\section{Perceptions of differential funding for Uganda and Kenya}

Because of the different paces in project implementation in Kenya and Uganda, DDPSC stated that its relationship with KARI had not matured, as it did with NARO, and that the former was not delivering the same kinds of results as the latter had been. One interviewee explained that the progress of the projects is influenced by the way in which funding is channeled to the African partners: while the activities in Uganda [NARO] are funded by the Monsanto Fund and the Danforth Centre, all the activities in Kenya [KARI] are funded by USAID. There were perceptions that, whereas Kenya received piecemeal funding for no more than one year at a time, Uganda received cash for a whole five-year phase. This means that the activities in Uganda ran uninterrupted, while those in Kenya experienced frequent and long intervals in which there was no work. The interviewee interpreted such differential funding as preferential treatment in favor of NARO and felt that KARI received less financial support and training opportunities than their Ugandan counterparts.

\section{Trust-building practices}

Interviewees identified several practices that contributed to enhancing trust among the partners in the project and with the community. Open and regular communication among the partners was the most talked about practice. One interviewee pointed out that there were no special exercises put in place specifically to foster trust; rather, trust was a result of the established management practices.

\section{Regular exchange visits by the partners}

An interviewee from NARO said that regular exchange visits among partners boosted trust in the partnership. The visiting partners were exposed to the ongoing project activities at laboratory and field levels and had the opportunity to present seminars about the project to the wider community in partner institutions, thus creating awareness of the project. Exchange visits between KARI and NARO were also opportunities for sharing germplasm and facilities such as greenhouses for experiments.

One interviewee from KARI recognized a direct connection among the visits, technical competence, and trust. He said the visits improved mutual understanding and trust between KARI and DDPSC, while making them more competent to talk about VIRCA. This in turn led to the achievement of project milestones and enhanced trust among partners. Another interviewee from KARI underscored the need to include the members in top management of the partner institutions and regulatory organizations in the exchange visits. He observed that this will give them an opportunity to appreciate the benefits of the project, therefore leading to enhanced trust institution-wide. Spielman, Hartwich and Grebmer [20] observed that PPPs could achieve greater success with face-to-face interaction, hands-on collaboration and scientific exchange programmes. The visits contributed to trust building as they provided the partners a forum in which to mingle with stakeholders and get their feel of the project.

\section{Training of scientists and other technical staff}

Before returning home as highly skilled people, the scientists being trained at DDPSC received exposure to extended periods of interaction with DDPSC staff during which they built trust with one another. This training was well received at home and was, according to an interviewee from NARO, one of the "key things that happened ... without [the need for] paying fees." We observe that the technical competence acquired was an important ingredient for trust building amid myths about biotechnology and its efficacy.

In addition, an interviewee from DDPSC recommended closer private sector involvement to complement public sector competence, especially on regulatory matters. He noted that successful commercialization of technologies from research all over the world has been associated with active involvement of the private sector 
in the implementation of projects. With this kind of involvement, the trained scientists are likely to benefit from unique private sector expertise and experience with the regulatory aspects, which will enhance the former's ability to comply with the law. Ultimately, this will improve trust between the partners and regulators.

\section{Open and regular communication between the partners}

Open communication was achieved by involving the partners in the initial setting of project goals; holding biweekly teleconferences; having face-to-face interactions; and regularly reporting on project activities. These procedures provided an opportunity for sharing information and having open discussions in which partners could provide feedback to one another - all of which helped resolve any issues that could potentially arise, thus creating positive group dynamics conducive to building trust. At the same time, bi-annual and annual financial and technical reports were regularly shared among the stakeholders, which helped enhance trust among the partners.

One interviewee, however, pointed out that trust among the VIRCA partners was not very high, due to some shortcomings - notably, the lack of knowledge of the kind of agreement DDPSC had with NARO and lack of an agreement between NARO and KARI. This suggests that the flow of information may not have been all-round, which, as observed by one interviewee, may be counterproductive to trust building particularly with regards to product sharing between the two African countries. Hall [26] recommends that in order for PPPs in agricultural systems to realize full potential, new ways are needed to break down barriers and increase communication and trust between the public and the private sector partners.

\section{Clear definition of roles and responsibilities}

VIRCA partners had well-defined roles so each partner was held accountable for the outcomes. Appropriate assignment of roles and responsibilities is helpful in dealing with cases of internal conflict among partners [20]. VIRCA partners recognized this early and therefore entered into a memorandum of understanding before the project started, according to an interviewee from NARO. One interviewee partly attributed the high level of trust and accountability among the partners to documents, reports, and agreed upon responsibilities and expectations. The clear definition of roles and expectations served as a foundation for building trust.

Interviewees emphasized the need for, and importance of, drafting a detailed agreement immediately upon commencement of the project that stipulates the individual partners' contributions; roles; ownership; and use of intellectual property rights (IPRs). The agreement should clearly convey if a company's IPRs are being licensed royalty-free, for example. Such an agreement is necessary in order to prevent challenges midway through the project, as witnessed in the Insect Resistant Maize for Africa
(IRMA) project in Kenya, which was a research-only license [27].

Institutional and individual commitment to succeed One interviewee from DDPSC said: All the people working on the project really need to put intensive effort into making sure that it is going correctly. Choosing staff with excellent academic and scientific credentials and personal interest in the success of the project was recognized as a great asset to the VIRCA project. These are people who, even when other attractive opportunities arise, would give VIRCA priority, while recognizing that transitions would likely slow the project's progress.

The partner organizations comprising the VIRCA project were recognized as committed to the project and did not treat it as a peripheral activity. Such institutional support helped spur individual scientists to commit to achieving sustainability and positive outcomes. The enthusiasm of scientists from NARO to the highest level of management endeared them to DDPSC. On the other hand, Kenya's [KARI's] apparent reluctance to engage with DDPSC may have led to a "bumpy" relationship, particularly in the early stages of the partnership, according to an interviewee from DDPSC.

\section{Conclusions}

Based on the findings of the study, we have derived four key lessons that other agbiotech PPPs may apply in building trust among partners and with the community. First, trust between partners may be adversely impacted by negative perceptions propagated about the capacity of partner institutions and individuals. Misperceptions may misrepresent character and thereby overlook the actual strengths and weaknesses of the individual or institution. Unless such perceptions are handled tactfully, the absence of reciprocated trust cannot produce an environment conducive to an effective partnership. Entering into a partnership should happen on a clean slate, devoid of negative perceptions pertaining to the capacity of the partners. This will provide a good foundation for trust building.

Second, the success of agbiotech projects in Africa is anchored on the delivery of milestones, which is also dependent on the competence of the institutions and individuals engaged in the projects. This study shows that technical and infrastructural capacity support for regulatory processes is necessary for the success of agbiotech PPPs. As regulatory arrangements in subSaharan African countries are slowly evolving, there will be a need for technical, financial and infrastructural support from partners from more developed countries, both at the national and institutional level. Private sector technical capacity and experience is therefore necessary to enable fast tracking of regulatory approvals, which would contribute to the enhancement of trust among partners. 
Third, detailed agreements and open and transparent practices during project implementation are necessary to dispel perceptions of partner inequality. We observe that regular exchange visits and open and regular communication will prevent the development of such perceptions about other partners and allow the partners to have an understanding of each other's circumstances. Detailed collaborative agreements stipulating partner roles and responsibilities would also contribute to easing any tensions that may arise from feelings of inequality. Such agreements offer a sense of security to the partners and make partners accountable to one another, leading to a sense of enhanced trust among the partners.

Lastly, institutional and individual commitment to succeed is necessary for agbiotech PPPs to be successful. In the absence of adequate and sufficient experiential background information on the individual partners, the VIRCA partnership depended on the commitment and enthusiasm of the organizations and individuals for the initiation and initial progress of the project. This provided a foundation for partners to build trust with one another, as evidenced by consistent provision of funding for the project, identification of committed and qualified persons, and the partner institutions' ownership of the project. Institutional commitment provides an opportunity for partner interaction and spurs individual scientists to be more committed in the project. This commitment, and the trust that ensues, are likely to contribute to sustained research activities beyond the project life.

\section{Endnotes}

${ }^{a}$ Food security exists when all people, at all times, have physical, social and economic access to sufficient, safe and nutritious food which meets their dietary needs and food preferences for an active and healthy life. URL: http://www.fao.org/docrep/005/y4671e/y4671e06.htm

${ }^{\mathrm{b}}$ BioCassava Plus is a project managed by Donald Danforth Plant Sciences Centre and operating in Africa, Asia, Europe, Latin America and North America whose objective is to reduce malnutrition among the 250 million people in sub-Saharan Africa who rely on cassava as their staple food by delivering a more nutritious and marketable cassava.

'Sweden's Africa Wars. URL: http://www.ethnopress. se/NewAfrican_Nilsson.pdf. Accessed $20^{\text {th }}$ June 2011

\section{Additional material}

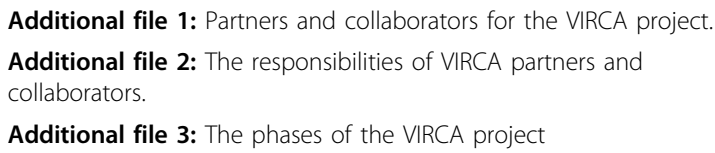

Additional file 3: The phases of the VIRCA project

Additional file 4: Sample questions from open-ended interview guide

\section{Acknowledgements}

The authors are grateful to each of the participants who contributed substantial time and effort to this study. The authors also thank Hassan Massum and Jessica Oh for comments on earlier drafts of the manuscript. This project was funded by the Bill \& Melinda Gates Foundation and supported by the Sandra Rotman Centre, an academic centre at the University Health Network and University of Toronto. The findings and conclusions contained within are those of the authors and do not necessarily reflect official positions or policies of the foundation.

This article has been published as part of Agriculture \& Food Security Volume 1 Supplement 1, 2012: Fostering innovation through building trust: lessons from agricultural biotechnology partnerships in Africa. The full contents of the supplement are available online at http://www.agricultureandfoodsecurity.com/ supplements/1/S1. Publication of this supplement was funded by the Sandra Rotman Centre at the University Health Network and the University of Toronto. The supplement was devised by the Sandra Rotman Centre.

\section{Author details}

${ }^{1}$ Sandra Rotman Centre, University Health Network and University of Toronto, Toronto, Ontario, Canada. ${ }^{2}$ African Centre for Innovation and Leadership Development, Federal Capital Territory, Abuja, Nigeria. ${ }^{3}$ Dalla Lana School of Public Health, University of Toronto, Toronto, Canada. ${ }^{4}$ Grand Challenges Canada. ${ }^{5}$ Dalla Lana School of Public Health and Department of Surgery, University of Toronto, Toronto, Canada.

\section{Authors' contributions}

Study conception and design: OCE, JM and ASD. Data collection: JM and OCE. Analysis and interpretation of data: JM and OCE. Draft of the manuscript: JM and OCE. Critical revision of the manuscript for important intellectual content: OCE, JM and ASD. All authors read and approved the final manuscript.

\section{Competing interests}

The authors declare that they have no competing interests.

Published: 1 November 2012

\section{References}

1. Answers.com. [http://www.answers.com/topic/cassava].

2. IITA. [http://www.iita.org/cassava].

3. FAOSTAT. [http://faostat.fao.org/site/567/DesktopDefault.aspx? PagelD=567\#ancor].

4. BioVision. [http://www.biovisioneastafrica.com/publications/cassava_article. pdf].

5. Takeshima H: Prospects for Development of Genetically Modified Cassava in Sub-Saharan Africa. AgBioForum 2010, 13(1):63-75.

6. Bhattacharjee R: Harnessing Biotechnology for Conservation and Increased Utilization of Orphan Crops. ATDF JOURNAL 2009, 6(3):24-33.

7. Patil BL, Fauquet CM: Cassava mosaic geminiviruses: actual knowledge and perspectives. Mol Plant Pathol 2009, 10:685-701.

8. ReliefWeb. [http://reliefweb.int/node/300344].

9. Legg J, Whyte J, Kapinga R, Terri J: Management of cassave mosaic disease pandemic in East Africa. In Whiteflies and whitefly-borne viruses in the tropics: building a knowledge base for global action. Colombia: Centro Internacional de Agricultura Tropical;Anderson PK, Morales F. Cali 2005:332-338.

10. Alicai T, Omongo CA, Maruthi MN, Hillocks RJ, Baguma Y, Kawuki R, Bua A Otim-Nape GW, Colvin J: Re-emergence of Cassava Brown Streak Disease in Uganda. Plant Disease 2007, 91(1):24-29.

11. Mbanzibwa D, Tian Y, Tugume A, Patil BL, Yadav JS, Bagewadi B, Abarshi MM, Alicai T, Changadeya W, Mkumbira J, Muli MB, Mukasa S, Tairo F, Baguma Y, Kyamanywa S, Kullaya A, Maruthi MN, Fauquet C, Valkonen JPT: Evolution of cassava brown streak disease-associated viruses. Journal of General Virology 2011, 72:974-987.

12. Among B: Deadly cassava disease hits Uganda. New Vision 25 May 2010, Archive.

13. McNeil DG: Virus Ravages Cassava Plants in Africa. The New York Times May 31 2010, Science.

14. Donald Danforth Plant Science Centre: Donald Danforth Plant Science Centre: The Leaflet. 2009, 11(1):1-12. 
15. Donald Danforth Plant Science Center. [http://www.danforthcenter.org/ wordpress/?p=6776].

16. Monsanto Fund: Monsanto Fund: Global Contributions Report 2006-2007. 2007, 1-42.

17. Proceedings of the 1st all Africa Congress on Biotechnology: 22-26 September 2008; Nairobi, Kenya. African Biotechnology Stakeholders Forum;Nzuma JM 2008:

18. Donald Danforth Plant Science Center. [http://www.danforthcenter.org/ wordpress/?page_id $=188 \&$ catid $=10 \&$ banner $=$ science/images $/$ bannerprograms.jpg\&side=science/programs/international_programs/virca/sidebarvirca.php\&nav=science\&p1=INTERNATIONAL_PROGRAMS\&p2=VIRCA].

19. Zheng J, Roehrich J, Lewis MA: The dynamics of contractual and relational governance: Evidence from long-term public-private procurement arrangements. Journal of Purchasing and Supply Management 2008, 14:43-54.

20. Spielman DJ, Hartwich F, von Grebmer K: Public-Private Partnerships in International Agricultural Research. International Food Policy Research Institute 2007, 9:1-6.

21. Spielman DJ, Grebmer K: Public-Private Partnerships in International Agricultural Research: An Analysis of Constraints. Journal of Technology Transfer 2006, 31:391-300

22. Ezezika OC, Daar AS, Barber K, Mabeya J, Thomas F, Deadman J, Wang D, Singer PA: Factors influencing agbiotech adoption and development in sub-Saharan Africa. Nature Biotechnology 2012, 30:38-40.

23. Ezezika OC, Thomas F, Lavery JV, Daar AS, Singer PA: A Social Audit Model for Agro-biotechnology Initiatives in Developing Countries: Accounting for Ethical, Social, Cultural and Commercialization Issues. Journal of Technology Management and Innovation 2009, 4(3):24-33.

24. Hawkins R, Heemskerk W, Booth R, Daane J, Maatman A, Adekunle AA: Integrated Agricultural Research for Development (IAR4D). A Concept Paper for the Forum for Agricultural Research in Africa (FARA) SubSaharan Africa Challenge Programme (SSA CP). 2009, 1-92.

25. Virgin I, Bhagavan M, Komen J, Kullaya A, Louwaars N, Morris EJ, Okori P, Persley G: Agricultural biotechnology and small-scale farmers in Eastern and Southern Africa. 2007.

26. Hall A: Public private sector partnerships in an agricultural system of innovation: concepts and challenges. 2006, 1-33.

27. KARI, CIMMYT: Insect Resistant Maize for Africa Annual Report 2006. 2006, 27:1-140.

doi:10.1186/2048-7010-1-S1-S7

Cite this article as: Ezezika et al: Building effective partnerships: the role of trust in the Virus Resistant Cassava for Africa project. Agriculture \& Food Security 2012 1(Suppl 1):S7.

\section{Submit your next manuscript to BioMed Central and take full advantage of:}

- Convenient online submission

- Thorough peer review

- No space constraints or color figure charges

- Immediate publication on acceptance

- Inclusion in PubMed, CAS, Scopus and Google Scholar

- Research which is freely available for redistribution

Submit your manuscript at www.biomedcentral.com/submit
C Biomed Central 